\title{
Update on potential medical treatments for encapsulating peritoneal sclerosis; human and experimental data
}

\author{
Tom Cornelis • Dimitrios G. Oreopoulos
}

Received: 23 February 2010/Accepted: 14 April 2010/Published online: 7 May 2010

(C) The Author(s) 2010. This article is published with open access at Springerlink.com

\begin{abstract}
Encapsulating peritoneal sclerosis (EPS) is an infrequent but serious complication of peritoneal dialysis (PD). The pathogenesis is unknown but speculation is ongoing. The current management of EPS focuses on prevention and treatment of the inflammatory and fibrotic changes at the level of the peritoneal membrane with immunosuppressive and antifibrotic agents, respectively. This article reviews the currently available human and animal data on potential agents to prevent and/or treat EPS. We propose a strategy for early diagnose EPS in an attempt to avoid the development of the full-blown and potentially life-threatening clinical syndrome of EPS. Future research should focus on studying potential prophylactic and therapeutic agents in humans in large, multicenter, randomized trials but also on early detection of EPS in the inflammatory phase by means of biomarkers and the establishment of a composite EPS score.
\end{abstract}

Keywords Peritoneal dialysis . Encapsulating peritoneal sclerosis . Prevention - Treatment

T. Cornelis $(\bowtie) \cdot$ D. G. Oreopoulos Division of Nephrology, University Health Network, University of Toronto, Toronto, ON, Canada e-mail: tomcor77@gmail.com

\section{Introduction}

Encapsulating peritoneal sclerosis (EPS) is a rare but potentially life-threatening complication of peritoneal dialysis (PD). After a period of 1-3 years on PD, all patients develop simple peritoneal sclerosis, but only few of them will progress to the syndrome of EPS that potentially consists of ultrafiltration failure with a high transport status, intermittent small-bowel obstruction and/or weight loss [1]. On abdominal imaging with computed tomography (CT), peritoneal thickening, adhesions of bowel loops, signs of obstruction and fluid collections are usually present [2]. The high morbidity and mortality of EPS is attributed to malnutrition and sepsis. The prevalence of EPS varies between 0.5 and $7.3 \%$ but may increase to as high as $15.2 \%$ in patients on PD for more than 15 years [3]. EPS frequently occurs after cessation of $\mathrm{PD}$, perhaps because cessation of lavage may lead to accumulation of fibrin, cytokines and growth factors, leading to inflammation and fibrosis. EPS is also common in the post-transplant period [4], possibly because of the current tendency to decrease the dose of prednisone in transplantation together with the use of pro-fibrotic calcineurin inhibitors (CNI). The etiology of EPS is unclear but the speculation is a 'two-hit' hypothesis. The use of bio-incompatible solutions (containing glucose, glucose-degradation products and lactate in an acid solution) and exposure to toxins such as plasticizers and chlorhexidine leads to loss of normal mesothelial cell morphology, 
expansion of the submesothelial subcompact zone (epithelial-to-mesenchymal transition) and also to neovascularization [5]. This is considered to be the 'first hit' in the development of EPS. The 'second hit' is often discontinuation of PD, an episode of severe PD peritonitis or any other peritoneal trauma such as abdominal surgery. A genetic predisposition to this second hit might put some patients at higher risk for developing EPS. Enhanced production of transforming growth factor beta (TGF-beta) and vascular endothelial growth factor (VEGF) plays a central role in fibrosis and neoangiogenesis, the two basic mechanisms in the pathogenesis of EPS [6].

The treatment of EPS is still controversial but is most often proposed to be a combination of cessation of PD as well as the use of immunosuppressive and antifibrotic agents together with nutritional support. Surgical intervention with enterolysis and decortication is common practice in Japan but less frequent in other parts of the world [7].

This review focuses on the reported use and benefits of immunosuppressive and antifibrotic agents in EPS. We reviewed through an extensive PubMed search the currently available human as well as animal data for the prevention and treatment of EPS.

\section{Human data on medical treatment for EPS}

\section{Tamoxifen}

Tamoxifen is a selective estrogen receptor modulator (SERM) that inhibits the production of TGF-beta by fibroblasts. It has been used in the past in several fibrosing syndromes such as retroperitoneal fibrosis and fibrosing mediastinitis [8].

Guest recently summarized the available clinical data for the usage of tamoxifen in EPS [9]. Between 1992 and 2007, 14 different groups have reported on their experience with tamoxifen therapy for EPS. The number of patients varied between 1 and 14 in each group. In total, 36 patients were studied. Twenty-one patients received tamoxifen as sole therapy, 8 patients were also treated with steroids (of which 1 patient also received azathioprine), 2 patients received rapamycin together with tamoxifen and 5 patients underwent surgery in conjunction with tamoxifen treatment. Doses of tamoxifen varied between 10 and $80 \mathrm{mg}$ per day. In 2 patients, the outcome was reported as 'resolved', 20 patients 'improved', 14 patients remained 'stable', 4 patients died and in 1 patient the outcome was not reported.

Del Peso extended the use of tamoxifen to patients with pre-EPS changes in a non-randomized study [10]. A total of $23 \mathrm{PD}$ patients with peritoneal sclerosis, who had ultrafiltration failure and a high transport status but without the typical CT findings for EPS, were studied for a period of 47 (tamoxifen group) and 29 (control group) months. None of the 9 patients in the 'tamoxifen as prophylaxis' arm did progress to full-blown EPS. However, 4 of the 14 patients in the control group who did not receive tamoxifen developed EPS and died. Tamoxifen dose in this study was $40 \mathrm{mg}$ per day; steroids were not used.

Tamoxifen is generally well tolerated. Potential side effects include hot flushes, nausea, fatigue, endometrial carcinoma and deep venous thrombosis. Evidently, randomized, controlled trials are necessary to assess the efficacy of tamoxifen for prophylactic and therapeutic management of EPS. Particulary interesting is indeed the idea to start treating EPS in the early stages with tamoxifen. This could be applied to patients on long-standing PD, who develop ultrafiltration failure with a high transport status but who do not have the typical imaging changes as expected in EPS.

\section{Glucocorticoids}

In 1997, Mori and colleagues reported for the first time on the successful use of steroids alone in one patient with EPS [11]. In 1999, Martins and colleagues also reported on one patient who was successfully treated for EPS with prednisone $100 \mathrm{mg}$ per day, tapered to be stopped over 4.5 months [12]. The patient responded excellently with recovery of lost weight, normalization of serum albumin and disappearance of the "cocooning' on CT of his abdomen. This patient also received azathioprine $50 \mathrm{mg}$ per day for 2.5 months. In 2001, Kuriyama and Tomonori reported on their experience in the treatment of EPS before and after 1997, the year wherein the decision was made to treat all EPS patients with prednisolone $0.5 \mathrm{mg} / \mathrm{kg}$ per day [13]. All 6 patients before 1997 died as a consequence of EPS, and all 5 patients treated after 1997 were alive and doing well. The use of steroids for the treatment of EPS was subsequently confirmed as a successful strategy in a rat 
model [14]. In this study, peritoneal fibrosis was induced in 20 rats by an acid dialysis solution. Glucocorticoid treatment prevented the progression of peritoneal fibrosis and adhesion of peritoneum. Dejagere and colleagues presented a patient who developed EPS after renal transplantation and who was successfully treated with high doses of corticosteroids [15]. A subsequent relapse, most likely due to fast tapering of the steroid dose, responded well to an increase in the steroid dose.

The pharmacological mode of corticosteroid action on EPS is still unknown. However, the speculation is that it may be via both the antiinflammatory effect and the immunosuppressive effect of it. Matsuo et al. [16] recently showed, in a rat model, that prednisolone inhibits the glucosemediated induction of monocyte chemoattractant protein-1 (MCP-1), which is important in recruiting monocytes and promoting fibrosis in peritoneal sclerosis. Glucose is supposed to upregulate MCP1 through hyperosmolarity by activating protein kinase C (PKC) and its downstream NF-kappa B signaling.

\section{Azathioprine}

Azathioprine (AZA) has shown advantages in anecdotal case reports in humans. Wong and colleagues reported on two patients with EPS who were treated with AZA [17]. The first patient was started on AZA $125 \mathrm{mg}$ per day $(1.5 \mathrm{mg} / \mathrm{kg} /$ day $)$ and prednisolone $30 \mathrm{mg}$ per day. Gastro-intestinal symptoms improved quickly, and his body weight and serum albumin normalized, and subsequently, AZA was gradually tapered to $75 \mathrm{mg}$ per day and prednisolone to $20 \mathrm{mg}$ per day. The second patient reported by Wong et al. made a full recovery within 4 weeks of starting the dual immunosuppressive treatment. Junor et al. [18] suggested the beneficial role of AZA in EPS from the finding that five PD patients who developed EPS after renal transplant had a prolonged survival with or without functioning graft, when compared to twelve PD patients who were not on immunosuppression and died within a year after developing EPS. He attributed the benign EPS course of the renal transplant patients to AZA being part of the immunosuppressive regime.

They hypothesized that immunosuppression suppresses the uncontrollable fibrogenesis and the inflammatory infiltrate of the peritoneal membrane that causes EPS.

A recent animal study with 52 non-uremic rats with EPS, however, could not show any benefit of AZA for the treatment of EPS [19]. In the steroid group on the other hand, there was a lower fibrosis score and less peritoneal thickness when compared to the control animals.

Mycophenolate mofetil

Mycophenolate mofetil (MMF) has been shown to be efficacious for EPS treatment in three patients reported by Lafrance et al. [20]. The first patient received colchicine $0.6 \mathrm{mg}$ per day, prednisone $50 \mathrm{mg}$ per day for 2 weeks with progressive tapering to $25 \mathrm{mg}$ per day and MMF $500 \mathrm{mg}$ twice a day. Her general condition improved dramatically together with resolution of the abdominal pain syndrome and normalization of the serum albumin. A repeat CT abdomen showed less thickening of the peritoneal membrane and normal bowel loops. This patient underwent living donor kidney transplantation 1 year later. The second patient was treated with prednisone $25 \mathrm{mg}$ per day tapered over 2 months to $15 \mathrm{mg}$ per day together with MMF $500 \mathrm{mg}$ twice a day. Abdominal symptoms and fever resolved rapidly, and both prednisone and MMF were stopped after 6 months of treatment. The third patient was treated with prednisone $50 \mathrm{mg}$ per day and MMF $500 \mathrm{mg}$ twice per day with rapid clinical and radiological improvement. Both prednisone and MMF were held 2 months after initiation of the treatment because of disseminated herpes zoster.

All three patients showed significant improvement within a month after MMF was started in combination with steroids, and all three patients were still alive more than 2 years after EPS was diagnosed. None of them experienced a relapse. We question, however, whether it was the MMF or the concomitant use of steroids that had the greatest impact on the EPS course. No other data on the use of MMF in the treatment of EPS are available.

Conclusion on human data

Human data suggest that tamoxifen and steroids might be useful in the prevention and/or treatment of EPS. Data on AZA and MMF are scarce and weak. 
The reason why transplant recipients may be at higher risk to develop EPS, although being treated with steroids and AZA or MMF, lies, as stated before, in the use of lower steroid dose and in the use of CNI in current immunosuppressive regimes.

\section{Experimental data on medical treatment for EPS}

\section{Rosiglitazone}

Rosiglitazone is a peroxisome proliferator-activated receptor (PPAR) agonist. PPARs are the major regulators of key metabolic pathways of various inflammatory responses in fibrosing processes in most tissues. PPAR gamma receptors are expressed in mesothelial cells [21]. PPAR gamma plays a significant role in cell differentiation as well as in anti-inflammatory and antiangiogenic responses. They might therefore have a potential role in peritoneal defense. Bozkurt et al. [22] investigated the effect of rosiglitazone on progression and regression of EPS in 53 non-uremic rats with EPS. They found that rosiglitazone was more effective than peritoneal resting (leaving peritoneal cavity empty for 3 weeks till time of analysis after intraperitoneal chlorhexidine administration for initial 3 weeks) for almost all of the functional and structural peritoneal parameters, including an improvement in dialysate over plasma urea concentration (D/P urea) and ultrafiltration (UF) capacity and a decrease in inflammatory cell count and neoangiogenesis. These authors suggest that rosiglitazone may have a role in the prevention of EPS by inhibiting inflammation and neovascularization, especially in diabetes.

$N$-acetylcysteine

The well-known antioxidant $N$-acteylcysteine (NAC) is a capable reactive oxygen species (ROS) scavenger. Generation of ROS, as for instance by the presence of bio-incompatible PD solutions, might be responsible for progressive peritoneal membrane dysfunction and fibrosis. NAC also inhibits VEGF and decreases the activity of angiotensin II and TGFbetal in human peritoneal mesothelial cells [23].

The group of Bozkurt studied 39 non-uremic rats to assess the prophylactic and therapeutic effect of NAC in EPS [24]. NAC significantly improved peritoneal UF failure and neovascularization when compared with peritoneal resting. Surprisingly, there was no protective effect of NAC on fibrosis. However, the authors considered the decreased inflammation and vascularity to be promising for peritoneal membrane protection.

Colchicine

Colchicine is a well-known anti-inflammatory and antifibrotic agent. It also decreases the TGF-beta1 mRNA expression in idiopathic pulmonary fibrosis [25].

In a study of 48 non-uremic rats with EPS, colchicine resulted in significantly better UF volume when compared to the peritoneal resting group [26]. In the colchicine-regression group (intraperitoneal chlorhexidine for 3 weeks followed by colchicine in drinking water for 3 weeks), colchicine significantly improved peritoneal thickness and neovascularization compared to the resting group. In the colchicineprogression group (in which intraperitoneal chlorhexidine and oral colchicine were administered together during 3 weeks), there was a more pronounced effect of colchicine on fibrosis compared to the regression model. This finding might be compatible with the suggestion of an early inflammatory phase in the course of EPS and possibly confirms the need for early intervention before irreversible changes take place. In conclusion, colchicine was shown to have protective effects on membrane integrity via decreased inflammation, cell infiltration and vascularity.

Renin-angiotensin system inhibition

Angiotensin II promotes fibrosis and inflammation in various tissues via the enhanced gene expression of TGF-beta1, VEGF, epidermal growth factor (EGF), plasminogen activator inhibitor and pro-inflammatory cytokines. It plays an important role in fibrotic disease processes such as diabetic nephropathy, cardiac remodeling and hypertensive vasculopathy. The role of angiotensin II in peritoneal fibrosis has also been well described [27].

Sawada et al. [28] studied the antifibrotic effects of quinapril, an ACE inhibitor, on mice with EPS. Macroscopic examination revealed that fibrotic changes in the parietal peritoneum were statistically 
more significant in the group of animals in which EPS was induced with intraperitoneal chlorhexidine and ethanol compared to the animals in which intraperitoneal chlorhexidine and ethanol were administered together with oral quinapril. Histological examination demonstrated that peritoneal thickening was clearly improved in the quinapril group.

Kyuden et al. [29] showed, in a cultured human peritoneal mesothelial cell model, that perindopril and candesartan attenuated the increased production of TGF-beta1 and that they reduced cell proliferation caused by exposure to high glucose. These effects were greater with the combination of both drugs.

Nakamoto et al. [30] studied the effects of the orally administered angiotensin receptor blocker olmesartan versus the calcium channel blocker amlodipine on peritoneal fibrosis in 40 hypertensive rats in which EPS was induced by a glucosecontaining acid dialysis solution. Treatment with olmesartan prevented the progression of peritoneal fibrosis and adhesions, on which amlodipine did not have an impact.

In another non-uremic EPS rat model, the advantages of renin-angiotensin system (RAS) blockade in regression of EPS were studied [31]. The enalapril and valsartan group had better results with respect to UF volume and D/P urea when compared to the resting group. Surprisingly, these improvements were not present in the enalapril-valsartan combination group. Structural changes (peritoneal thickness and number of vessels) were ameliorated in all treatment groups compared to the resting group. In summary, RAS blockade seemed more effective than peritoneal resting with respect to ultrafiltration volume, vascularity and peritoneal thickness. Interestingly, dual blockade with enalapril and valsartan had no additional beneficial effects and even made some functional improvements disappear.

Human data on the effect of RAS inhibition on the peritoneal membrane are scarce. Kolesnyk and colleagues retrospectively analyzed data from 66 patients treated with PD for at least 2 years, during which at least 2 standard peritoneal permeability analyses (SPA) were performed [32]. Thirty-six patients were treated with an ACE inhibitor and/or ARB, 30 patients did not receive any of these agents. In the ACEinhibitor/ARB group, small solute transport had decreased, while it increased in the control group during the time on PD. The same group from the
Netherlands studied data from 217 long-term PD patients, of whom 120 were treated with an ACE inhibitor/ARB, 87 were not and 10 who had them for less than $25 \%$ of their time on PD [33]. The value of the 24-h D/P creatinine was correlated with PD duration $(P=0.01)$, but the slope of the rise of $\mathrm{D} / \mathrm{P}$ creatinine over time was less steep in the group treated with RAS inhibition $(P=0.05)$. Increase in small solute transport due to peritoneal inflammation and/or fibrosis is a well-known early sign of EPS. The presented human data suggest that RAS inhibition may play a role in preventing EPS in PD patients. Wong et al. [34] showed that ACE activity is independently associated with mortality in diabetic PD patients. Apart from its role in macroangiopathy, increased ACE activity might also be associated with the development of EPS and hence explain its association with mortality in PD patients. This is also compatible with data from Fang et al. [35], showing that treatment with ACE inhibitor and/or ARB in PD patients was associated with a dramatically reduced mortality independent of blood pressure and other clinical and demographic variables.

Thalidomide

Thalidomide suppresses the production of tumor necrosis factor (TNF) alpha by macrophages and $\mathrm{T}$ cells, and based on its immunomodulatory, antiinflammatory and antiangiogenic effects, it may have a role in the treatment of EPS [36].

Based on this rationale, Mondello and colleagues induced EPS in 40 rats by intraperitoneal administration of chlorhexidine, and thalidomide was given orally [37]. Thalidomide reduced the extent and severity of histological signs of peritoneal injury as well as the degree of polymorphonuclear cell infiltration in injured peritoneum. It also resulted in reduction of the expression in the tissue of TNFalpha, TGF-beta, VEGF and NF-kappa B activation.

\section{Everolimus}

Everolimus is a macrolide immunosuppressive agent that inhibits the activity of mammalian target of rapamycin (mTOR), a cellular enzyme that plays a key role in cell growth and proliferation. The antifibrotic effects of mTOR inhibitors are well described [38-40]. 
Duman studied the effects of everolimus in a nonuremic EPS rat model [41]. Everolimus was more effective than peritoneal rest with regard to vascularity and peritoneal thickness. It had beneficial effects on UF failure, inflammation and fibrosis.

Other experimental agents

More experimental data are available for the treatment of EPS. However, none of these agents are currently used in clinical practice to treat other diseases. This is in contrast to the previously described agents. An excellent review of all these experimental data for the treatment of EPS was written by Park and colleagues [6]. Agents such as pirfenidone (inhibits the expression of TGF-beta 1 and TNF-alpha and scavenges reactive oxygen species) [42], antiangiogenic strategies with anti-VEGF neutralizing antibodies [43], TPN-470 [44] and endostatin peptide [45] as well as oligonucleotides against the collagen accumulating heat shock protein 47 (HSP-47) [46], ONO 487 (reduces the expression of MMP-2, TGF-beta and VEGF and subsequent accumulation of type I collagen) [47], chimeric DNA-RNA hammerhead ribozyme targeting TGF-beta mRNA [48] and hepatocyte growth factor [49] are discussed. Stabilization of D/P creatinine over time on PD has also been reported in a PD patient with metastatic renal cell carcinoma treated with the tyrosine kinase inhibitor sunitinib that also has anti-VEGF effects [50].

\section{Biocompatible PD solutions}

Numerous factors related to the composition of standard peritoneal dialysis solutions possibly contribute to the pathogenesis of peritoneal fibrosis during PD, including glucose, glucose-degradation products [51], high osmolarity, low $\mathrm{PH}$, lactate and plasticizers released from the PD bags.

Garosi showed in a rabbit model that PD solutions containing amino acids did not cause mesothelial damage as opposed to solutions containing glucose [52]. Submesothelial edema was worse in rabbits dialyzed with glucose solution when compared to amino acid solution, and within the glucose-containing dialysate group, the edema was worst in the highest glucose group. No difference in submesothelial infiltration was found between the groups.

The use of biocompatible solutions has been advocated for in an attempt to prevent the development of EPS [53]. However, to date, no definitive human data are available to support the use of biocompatible solutions for this purpose.

Recently, Yao and colleagues studied conventional and biocompatible PD solutions in a rat model [54]. Twenty-eight rats were dialyzed three times daily for 4 weeks with a conventional or biocompatible solution each with various glucose concentrations. The use of conventional solutions, especially the highest glucose-containing ones, resulted in the expansion of the submesothelial compact zone, loss of mesothelial cell layer integrity, hypercellularity, accumulation of collagen, increased vessel numbers and increased TGF-beta1 expression, but this did not significantly change fluid and solute peritoneal transport characteristics.

Van Westrhenen et al. [55] investigated in a rat model whether a filter-sterilized pyruvate-buffered dialysis solution, made by combination of low concentrations of amino acids, glycerol and glucose (PYRAGG), would induce less peritoneal abnormality than glucose/lactatebased peritoneal solutions. No differences with respect to peritoneal transport were found between the different groups. However, histological assessment of the peritoneum revealed that the PYRAGG group had lower degree of fibrosis and neoangiogenesis than the 2 other groups. They concluded that a combination of osmotic agents (each in lower concentration) rather than the use of glucose alone (in high concentration) might help in the prevention of neoangiogenesis and fibrosis and therefore EPS.

Whether the use of biocompatible solutions could prevent the development of EPS is unclear as stated before. Prolonged (longer than 3 years), large, randomized trials are lacking to address this question. In a recent editorial, Tejde et al. [56] reported on 2 patients who developed EPS even though they were treated only with biocompatible solutions. However, both patients had multiple episodes of PD peritonitis possibly explaining why they developed EPS, even in the presence of biocompatible solutions in the peritoneal cavity.

\section{Conclusions}

Encapsulating peritoneal sclerosis (EPS) is a rare but potentially dangerous complication in PD patients. The exact pathogenesis is unfortunately not well 
understood. Current treatment focuses on the inflammatory and fibrotic responses of the disease.

Some clinical experience in patients with EPS is only available with tamoxifen and prednisone. However, partly due to the low number of patients with EPS, there is a lack of large, randomized, controlled trials. Awaiting further evidence and based on this clinical experience, we support the use of tamoxifen and prednisone for the treatment of EPS and also for prophylaxis in the early inflammatory phase of EPS. A daily dose of 20-mg tamoxifen seems to have only minimal side effects. However, a dose up to $40 \mathrm{mg}$ per day may be required for prevention of EPS [10]. Follow-up for thrombotic complications and endometrial cancer is essential.

The case reports on the effects of MMF and AZA in patients with EPS are insufficient to draw conclusions that would influence daily clinical practice.

Recent animal data with rosiglitazone, $\mathrm{N}$-acteylcysteine, colchicine, RAS blockade, thalidomide and everolimus are promising. However, in the absence of further studies of these agents in patients with EPS, we deem it difficult to support their systematic use for the treatment of EPS. On the other hand, treating diabetic PD patients with rosiglitazone, trying to start all PD patients with hypertension on an ACE inhibitor and finally promoting the use of mTOR inhibitors instead of CNI in PD patients who receive a kidney transplant, do not seem to be unreasonable suggestions.

\section{Future directions}

Future EPS research should not only focus on the optimization of anti-inflammatory and antifibrotic treatment of EPS but also on the early detection of the inflammatory EPS phase (Fig. 1). Because of the non-specificity of the clinical syndrome that often accompanies the early phase of EPS, biomarkers might be particularly useful. Serum markers such as CRP, albumin and beta2-microglobulin [57] may be useful. Effluent markers such as CA-125, IL-6, VEGF [58], TGF-beta, matrix metalloproteinase (MMP-2) [59], fibrin-degradation products (FDP) [60, 61], white cell count with differentiation and hyaluronan levels [62] have been shown in the past to be associated with inflammation, tissue remodeling and peritoneal membrane injury, and even increased solute transport.
Sampimon and colleagues analyzed the time course of CA-125 and IL-6 preceding the diagnosis of EPS [63, 64]. They showed that an appearance rate of CA-125 lower than $33 \mathrm{U}$ per minute and of IL-6 higher than $350 \mathrm{pg}$ per minute in patients with ultrafiltration failure had a sensitivity of $70 \%$ and a specificity of $89 \%$ for the diagnosis of EPS. They suggest that peritoneal samples should be taken regularly in PD patients to detect early peritoneal membrane inflammation. However, larger, randomized studies are necessary to look further into the detection and validation of these novel biomarkers for EPS.

In an attempt to facilitate the early diagnosis of EPS, we suggest that the nephrology community should aim at developing an EPS score. This EPS score could potentially consist of a combination of clinical, laboratory and radiological features (Table 1). Ideally, this EPS score should be monitored, for example, every 3-6 months and PD patients should be started on prophylactic EPS treatment with $20-40 \mathrm{mg}$ of tamoxifen per day and low-dose prednisone once the EPS score reaches a specific threshold. Large, randomized trials are obviously necessary to validate this strategy, and these trials should be initiated once the nephrology community agrees on the EPS score.

This proposed and hypothesized strategy of early detection of EPS in the inflammatory phase by means of an EPS score in combination with early treatment of EPS offers an alternative to the idea of an 'expiry date' for PD, which is propagated by some nephrologists as an attempt to try to prevent EPS from developing. Opposed to the principle of discontinuing PD according to pre-specified timing even before EPS is suspected, we strongly believe that individual evaluation of each PD patient based on clinical,

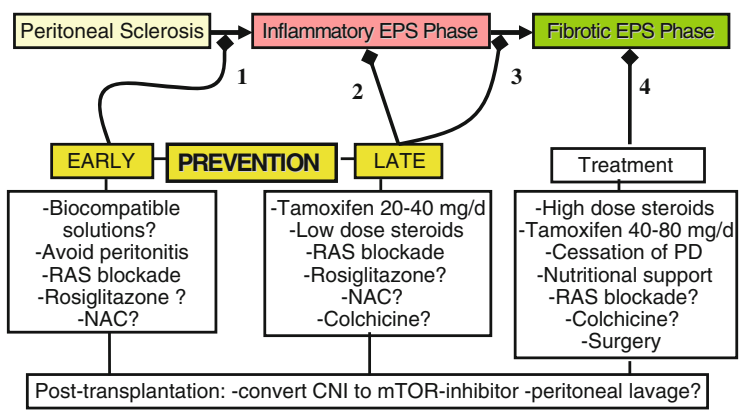

Fig. 1 Proposed options for prevention (arrows 1-3) and treatment (arrow 4) of encapsulating peritoneal sclerosis 
Table 1 Proposed components of a composite encapsulating peritoneal sclerosis score

\begin{tabular}{lll}
\hline Clinical & Laboratory & Radiological \\
\hline Ultrafiltration failure & PET: D/P creatinine-urea & X-ray abdomen: Peritoneal calcifications \\
PD-related complications: Hemoperitoneum, & Serum CRP, albumin, & Ultrasound: Progressive peritoneal membrane \\
inflow and outflow pain & beta2-microglobulin & thickening \\
& Effluent biomarkers: & CT abdomen: Progressive peritoneal thickening \\
& $\bullet$ CA-125 & and calcifications \\
& $\bullet$ IL-6 & \\
& $\bullet$ VEGF & \\
\hline
\end{tabular}

laboratory and radiological characteristics is a more valid approach to patients on long-standing PD treatment. Large, registry-based multicenter prospective studies are required to better understand and delineate the genetic, demographic and treatmentrelated risk factors contributing to the development of EPS. Awaiting the results of these studies, measures such as early use of tamoxifen, mTOR-inhibitorbased immunosuppressive regimes in transplantation, the use of biocompatible solutions and promoting the use of RAS inhibition in PD patients, should be the cornerstones in the prevention of the fibrotic phase of EPS rather than the systematic prescription of an 'expiry date' $[65,66]$.

Open Access This article is distributed under the terms of the Creative Commons Attribution Noncommercial License which permits any noncommercial use, distribution, and reproduction in any medium, provided the original author(s) and source are credited.

\section{References}

1. Nakamoto H (2005) Encapsulating Peritoneal Sclerosis-a clinician's approach to diagnosis and medical treatment. Perit Dial Int 25(Suppl 4):30-38

2. Vlijm A, Stoker J, Bipat S, Spijkerboer AM, Phoa SS, Maes R, Struijk DG, Krediet RT (2009) Computed tomographic findings characteristic for encapsulating peritoneal sclerosis: a case-control study. Perit Dial Int 29(5):517-522

3. Kawanishi H, Kawaguchi Y, Fukui H, Hara S, Imada A, Kubo H, Kin M, Nakamoto M, Ohira S, Shoji T (2004) Encapsulating peritoneal sclerosis in Japan: a prospective, controlled, multicenter study. Am J Kidney Dis 44(4):729737

4. Korte MR, Yo M, Betjes M, Fieren MW, van Saase JC, Boer WH, Weimar W, Zietse R (2007) Increasing incidence of severe encapsulating peritoneal sclerosis after kidney transplantation. Nephrol Dial Transplant 22(8): 2412-2414
5. Yañez-Mo M, Lara-Pezzi E, Selgas R, Ramirez-Huesca M, Dominguez-Jimenez C, Jimenez-Heffernan J, Aguilera A, Sanchez-Tomero JA, Bajo MA, Alvarez V, Castro MA, del Peso G, Cirujeda A, Gamallo C, Sanchez-Madrid F, LopezCabrera M (2003) Peritoneal dialysis and epithelial-tomesenchymal transition of mesothelial cells. N Engl J Med 348(5):403-413

6. Park SH, Kim YL, Lindholm B (2008) Experimental encapsulating peritoneal sclerosis models: pathogenesis and treatment. Perit Dial Int 28(Suppl 5):S21-S28

7. Kawanishi H, Moriishi M, Ide K, Dohi K (2008) Recommendation of the surgical option for treatment of encapsulating peritoneal sclerosis. Perit Dial Int 28(Suppl 3): 205-210

8. Van Bommel E, Hendriksz T, Huiskes A, Zeegers A (2006) Brief communication: tamoxifen therapy for non-malignant retroperitoneal fibrosis. Ann Intern Med 144(2):101-106

9. Guest S (2009) Tamoxifen therapy for encapsulating peritoneal sclerosis: mechanism of action and update on clinical experiences. Perit Dial Int 29(3):252-255

10. Del Peso G, Bajo A, Gil F, Aguilera A, Ros S, Costero O, Castro MJ, Selgas R (2003) Clinical experience with tamoxifen in peritoneal fibrosing syndromes. Adv Perit Dial 19:32-35

11. Mori Y, Matsuo S, Sutoh H, Toriyama T, Kawahara H, Hotta N (1997) A case of a dialysis patient with encapsulating peritoneal sclerosis successfully treated with corticosteroid therapy alone. Am J Kidney Dis 30(2):275-278

12. Martins LS, Rodrigues AS, Cabrita AN, Guimaraes S (1999) Sclerosing encapsulating peritonitis: a case successfully treated with immunosuppression. Perit Dial Int 19(5):478-481

13. Kuriyama S, Tomonari H (2001) Corticosteroid therapy in encapsulating peritoneal sclerosis. Nephrol Dial Transplant 16(6):1304-1305

14. Imai H, Nakamoto H, Fucshima R, Yamanouchi Y, Ishida Y, Suzuki H (2002) Glucocorticoid protect against the development of encapsulating peritoneal sclerosis on peritoneal dialysis. Adv Perit Dial 18:124-130

15. Dejagere T, Evenepoel P, Claes K, Kuypers D, Maes B, Vanrenterghem Y (2005) Acute- onset, steroid-sensitive, encapsulating peritoneal sclerosis in a renal transplant recipient. Am J Kidney Dis 45(2):e33-e37

16. Matsuo H, Tamura M, Kabashima N, Serino R, Tokunaga M, Shibata T, Matsumoto M, Aijima M, Oikawa S, Anai 
H, Nakashima Y (2006) Prednisolone inhibits hyperosmolarity-induced expression of MCP-1 via NF-kappaB in peritoneal mesothelial cells. Kidney Int 69(4):736-746

17. Wong CF, Beshir S, Khalil A, Pai P, Ahmad R (2005) Successful treatment of encapsulating peritoneal sclerosis with azathioprine and prednisolone. Perit Dial Int 25(3):285-287

18. Junor BJ, McMillan MA (1993) Immunosuppression in peritoneal sclerosis. Adv Perit Dial 9:187-189

19. Bozkurt D, Sipahi S, Cetin P, Hur E, Ozdemir O, Ertilav M, Sen S, Duman S (2009) Does immunosuppressive treatment ameliorate morphology changes in encapsulating peritoneal sclerosis? Perit Dial Int 29(Suppl 2):206-210

20. Lafrance JP, Létourneau D, Ouimet D, Bonnardeaux A, Leblanc M, Mathieu N, Pichette V (2008) Successful treatment of encapsulating peritoneal sclerosis with immunosuppressive therapy. Am J Kidney Dis 51(2): e7-e10

21. Zhang YF, Yang X, Zhang YJ, Sun YL, Zon XL, Kong QY, Dong XQ, Ye XQ, Yu XG (2006) Peroxisome proliferator-activated receptor-gamma is expressed by rat peritoneal mesothelial cells: its potential role in peritoneal cavity local defence. Am J Nephrol 26(6):602-611

22. Bozkurt D, Taskin H, Sezak M, Biçak S, Sen S, Ok E, Duman S (2008) Rosiglitazone, a peroxisome proliferatoractivated receptor agonist, improves peritoneal alterations resulting from an encapsulating peritoneal sclerosis model. Adv Perit Dial 24:33-38

23. Noh H, Kim JS, Han KH, Lee GT, Song JS, Chung SH, Jeon JS, Ha H, Lee HB (2006) Oxidative stress during peritoneal dialysis: implications in functional and structural changes in the membrane. Kidney Int 69:2022-2028

24. Bozkurt D, Hur E, Ulkuden B, Sezak M, Nar H, Purclutepe O, Sen S, Duman S (2009) Can N-acetylcysteine preserve peritoneal function and morphology in encapsulating peritoneal sclerosis? Perit Dial Int 29(Suppl 2):202-205

25. Tzortzaki EG, Antoniou MK, Zervou MI, Lambiri I, Koutsopoulos A, Tzanakis N, Plataki M, Maltezakis G, Bouros D, Siafakis NM (2007) Effects of antifibrotic agents on TGF-beta1, CTGF and IFN-gamma expression in patients with idiopathic pulmonary fibrosis. Respir Med 101(8):1821-1829

26. Bozkurt D, Bicak S, Sipahi S, Taskin H, Hur E, Ertilav M, Sen S, Duman S (2008) The effects of colchicine on the progression and regression of encapsulating peritoneal sclerosis. Perit Dial Int 28(Suppl 5):53-57

27. Noh H, Ha H, Yu MR, Kim YO, Kim JH, Lee HB (2005) Angiotensin II mediates high glucose-induced TGF-beta1 and fibronectin upregulation in HPMC through reactive oxygen species. Perit Dial Int 25:38-47

28. Sawada T, Ishii Y, Tojimbara T, Nakajima I, Fuchinoue S, Teraoka S (2002) The ACE inhibitor, quinapril, ameliorates peritoneal fibrosis in an encapsulating peritoneal sclerosis model in mice. Pharmacol Res 46(6):505-510

29. Kyuden I, Ito T, Masaki T, Yorioka N, Kohno N (2005) TGF-betal induced by high glucose is controlled by angiotensin-converting enzyme inhibitor and angiotensin II receptor blocker on cultured human peritoneal mesothelial cells. Perit Dial Int 25(5):483-491

30. Nakamoto H, Imai H, Fukushima R, Ishida Y, Yamanouchi Y, Suzuki H (2008) Role of the renin-angiotensin system in the pathogenesis of peritoneal fibrosis. Perit Dial Int 28(Suppl 3):S83-S87

31. Bozkurt D, Cetin P, Sepahi S, Hur E, Nar H, Ertilav M, Sezak M, Duman S (2008) The effects of renin-angiotensin system inhibition on regression of encapsulating peritoneal sclerosis. Perit Dial Int 28(Suppl 5):S38-S42

32. Kolesnyk I, Dekker FW, Noordzij M, le Cessie S, Struijk DG, Krediet RT (2007) Impact of ACE-inhibitors and ARB on peritoneal membrane transport characteristics in long-term PD patients. Perit Dial Int 27(4):446-453

33. Kolesnyk I, Noordzij M, Dekker FW, Boeschoten EW, Krediet RT (2009) A positive effect of ACE-inhibitors and $\mathrm{ARB}$ on peritoneal membrane function in long-term PD patients. Nephrol Dial Transplant 24:272-277

34. Wong TY, Szeto CC, Chow KM, Chan JC, Li PK (2002) Prognostic role of serum ACE activity on outcome of type 2 diabetic patients on chronic ambulatory peritoneal dialysis. Am J Kidney Dis 39(5):1054-1060

35. Fang W, Oreopoulos DG, Bargman JM (2008) Use of ACE inhibitors or angiotensin receptor blockers and survival in patients on PD. Nephrol Dial Transplant 23(11):3704-3710

36. Moreira AL, Sampaio EP, Zmuidzinas A, Frindt P, Smith KA, Kaplan G (1993) Thalidomide exerts its inhibitory action on tumour necrosis factor alpha by enhancing mRNA degradation. J Exp Med 177:1675-1680

37. Mondello S, Mazzon E, Di Paola R, Crisafulli C, Mondello P, Buemi M, Aloisi C, Cuzzocrea S (2009) Thalidomide suppresses encapsulating peritoneal sclerosis in a rat experimental model. Shock 32(3):332-339

38. Schuler W, Sedrani R, Cottens S, Häberlin B, Schulz M, Schuurman HJ, Zenke G, Zerwes HG, Schreier MH (1997) SDZ RAD, a new rapamycin derivative: pharmacological properties in vitro and in vivo. Transplantation 64(1):36-42

39. Cao W, Mohacsi P, Shorthouse R, Pratt R, Morris RE (1995) Effects of rapamycin on growth factor-stimulated vascular smooth muscle cell DNA synthesis. Inhibition of basic fibroblast growth factor and platelet-derived growth factor action and antagonism of rapamycin by FK506. Transplantation 59(3):390-395

40. Neef M, Ledermann M, Saegesser H, Schneider V, Reichen J (2006) Low-dose oral rapamycin treatment reduces fibrogenesis, improves liver function, and prolongs survival in rats with established liver cirrhosis. J Hepatol 45:786-796

41. Duman S, Bozkurt D, Sipahi S, Sezak M, Ozkan S, Ertilav M, Sen S, Ok E (2008) Effects of everolimus as an antiproliferative agent on regression of encapsulating peritoneal sclerosis in a rat model. Adv Perit Dial 24:104-110

42. Suga H, Teraoka H, Ota K, Komemushi S, Furutani S, Yamauchi S, Margolin S (1995) Preventive effect of pirfenidone against experimental sclerosing peritonitis in rats. Exp Toxicol Pathol 47(4):287-291

43. Io H, Hamada C, Ro Y, Ito Y, Hirahara I, Tomino Y (2004) Morphologic changes of peritoneum and expression of VEGF in encapsulating peritoneal sclerosis rat models. Kidney Int 65(5):1927-1936

44. Yoshio Y, Miyazaki M, Abe K, Nishino T, Furusu A, Mizuta Y, Harada T, Ozono Y, Koji T, Kohno S (2004) TNP-470, an angiogenesis inhibitor, suppresses the progression of peritoneal fibrosis in mouse experimental model. Kidney Int 66(4):1677-1685 
45. Tanabe K, Maeshima Y, Ichinose K, Kitayama H, Takazawa Y, Hirokoshi K, Kinomura M, Sugiyama H, Makino H (2007) Endostatin peptide, an inhibitor of angiogenesis, prevents the progression of peritoneal sclerosis in a mouse experimental model. Kidney Int 71(3):227-238

46. Nishino T, Miyazaki M, Abe K, Furusu A, Mishima Y, Harada T, Ozono Y, Koji T, Kohno S (2003) Antisense oligonucleotides against collagen-binding stress protein HSP47 suppress peritoneal fibrosis in rats. Kidney Int 64(3):887-896

47. Ro Y, Hamada C, Inaba M, Io H, Kaneko K, Tamino Y (2007) Inhibitory effects of matrix metalloproteinase inhibitor $\mathrm{ON}-4817$ on morphological alterations in chlorhexidine gluconate-induced peritoneal sclerosis rats. Kidney Int 22(10):2838-2848

48. Maruyama N, Fukuda N, Okada K, Matsumoto K (2007) Development of gene therapy for EPS by a chimeric DNARNA hammerhead ribozyme targeting TGF-betal mRNA. Nippon Jinzo Gokkai Shi 49(2):113-120

49. Matsuoka T, Maeda Y, Matsuo K, Naiki Y, Tamai Y, Sakaguchi M, Hasegawa H, Funauchi M, Kanamaru A (2008) Hepatocyte growth factor prevents peritoneal fibrosis in an animal model of encapsulating peritoneal sclerosis. J Nephrol 21:64-73

50. Tapiawala S, Bargman JM, Oreopoulos SG, Simons M (2009) The prolonged use of the tyrosine kinase inhibitor in a PD dialysis patient with metastatic renal cell carcinoma: possible beneficial effects on peritoneal membrane and peritonitis rates. Int Urol Nephrol 41(2):431-434

51. Krishnan M, Tam P, Wu G, Breborowicz A, Oreopoulos DG (2005) Glucose degradation products (GDP's) and peritoneal changes in patients on chronic PD: will new dialysis solutions prevent these changes? Int Urol Nephrol 37(2):409-418

52. Garosi G, Gaggiotti E, Monaci G, Brardi S, Di Paolo N (1998) Biocompatibility of a PD solution with amino acids: histological evaluation in the rabbit. Perit Dial Int 18(6):610-619

53. Devuyst O, Topley N, Williams JD (2002) Morphological and functional changes in the dialysed peritoneal cavity: impact of more biocompatible solutions. Nephrol Dial Transplant 17(Suppl 3):12-15

54. Yao Q, Pawlaczyk K, Ayala ER, Styszynski A, Breborowicz A, Heimburger O, Qian JQ, Stenvinkel P, Lindholm B, Axelsson J (2008) The role of the TGF/Smad signalling pathway in peritoneal fibrosis induced by peritoneal dialysis solutions. Nephron Exp Nephrol 109(2):e71-e78

55. van Westrhenen R, Vlijm A, Hiralall JK, Krediet RT (2008) Experimental study on long-term exposure to a biocompatible, hypertonic, pyruvate-buffered dialysis solution. Perit Dial Int 28(Suppl 5):S43-S47
56. Tejde M, Linder M, Karsberg M, Ekspong A (2010) The use of biocompatible solutions does not prevent development of encapsulating peritoneal sclerosis. Perit Dial Int 30(1):113-114

57. Yokoyama K, Yoshida H, Matsuo N, Maruyama Y, Kawamura Y, Yamamoto R, Hanaoka K, Ikeda M, Yamamoto H, Nakayama M, Kawaguchi Y, Hosoya T (2008) Serum beta2 microglobulin level is a potential predictor for encapsulating peritoneal sclerosis in PD patients. Clin Nephrol 69(2):121-126

58. Rodrigues A, Martins M, Santos MJ, Fonseca I, Oliveira JC, Cabrita A, Melo e Castro J, Krediet RT (2004) Evaluation of effluent markers CA-125, VEGF, and IL-6: relationship with peritoneal transport. Adv Perit Dial 24(4):347-352

59. Hirahara I, Inoue M, Okuda K, Ando Y, Muto S, Kusano E (2007) The potential of MMP-2 as a marker of peritoneal injury, increased solute transport or progression to encapsulating peritoneal sclerosis during $\mathrm{PD}-\mathrm{a}$ multicentre study in Japan. Nephrol Dial Transplant 22(2):560-567

60. Moriishi M, Kawanishi H (2008) Fibrin degradation products are a useful marker for the risk of encapsulating peritoneal sclerosis. Adv Perit Dial 24:56-59

61. Moriishi M, Kawanishi H, Tsuchiya S (2009) Peritoneal dialysis patients with high effluent fibrin degradation products. Adv Perit Dial 25:41-44

62. Parikova A, Zweers MM, Struijk DG, Krediet RT (2003) Peritoneal effluent markers of inflammation in patients treated with icodextrin-based and glucose-based dialysis solutions. Adv Perit Dial 19:186-190

63. Sampimon DE, Korte MR, Barreto DL, Vlijm A, de Waart DR, Struijk DG, Krediet RT (2010) Early diagnostic markers for encapsulating peritoneal sclerosis- a casecontrol study. Perit Dial Int 30(2):163-169

64. Krediet RT, Sampimon DE, Vlijm A, Coester AM, Struijk DG, Smit W (2009) Biological markers in the peritoneal dialysate: are they useful? Contrib Nephrol 163:54-59

65. Garosi G, Oreopoulos D (2009) No need for an 'expiry date' in chronic peritoneal dialysis patients to prevent encapsulating peritoneal sclerosis. Int Urol Nephrol 41(4):903-907

66. Kawaguchi Y, Tranaeus A, Lo WK, Di Paolo N, Nicolai G, Liakopoulos V, Dombros NV, Apostolou T, Perl J, Kawanishi H, Yang X, Yu X, Friedman EA, Bozkurt D, Duman S, Van Biesen W, Jeloka T, Sampimon DE, Vlijm A, Struijk DG, Krediet RT (2010) No need for an 'expiry date' in chronic peritoneal dialysis patients to prevent encapsulating peritoneal sclerosis: comments from around the world. Int Urol Nephrol 42(1):239-249 